\title{
Seepage Monitoring Models Study of Earth-Rock Dams Influenced by Rainstorms
}

\author{
Jianchun Qiu, ${ }^{1,2,3}$ Dongjian Zheng, ${ }^{1,2,3}$ and Kai $\mathrm{Zhu}^{2,3}$ \\ ${ }^{1}$ State Key Laboratory of Hydrology-Water Resources and Hydraulic Engineering, Hohai University, Nanjing 210098, China \\ ${ }^{2}$ National Engineering Research Center of Water Resources Efficient Utilization and Engineering Safety, Hohai University, \\ Nanjing 210098, China \\ ${ }^{3}$ College of Water-Conservancy and Hydropower, Hohai University, Nanjing 210098, China
}

Correspondence should be addressed to Jianchun Qiu; 121267184@qq.com

Received 20 November 2015; Revised 2 March 2016; Accepted 10 March 2016

Academic Editor: Sajid Hussain

Copyright (C) 2016 Jianchun Qiu et al. This is an open access article distributed under the Creative Commons Attribution License, which permits unrestricted use, distribution, and reproduction in any medium, provided the original work is properly cited.

For earth-rock dams influenced by rainstorms, seepage status monitoring is very important and provides the basis for the safe and effective operation of earth-rock dams. The most influential factors concerning the seepage of earth-rock dams are the reservoir water level, precipitation, temperature, and timeliness, and the influence of the reservoir water level and precipitation on the seepage of an earth-rock dam exhibits hysteretic effects. The reservoir water level of an earth-rock dam abruptly increases and may exceed the historically highest water level, therein causing new deformations of the earth-rock dam or even plastic deformation. Thus, the permeability coefficient for parts of an earth-rock dam changes, and we present the exceeded water level factor. Considering the complexity of the seepage monitoring of earth-rock dams, based on the hysteretic reservoir water level and precipitation, temperature, timeliness, and the exceeded water level factor, a statistical model based on an explicit function and an artificial wavelet neural network model based on an implicit function are established. Based on these two models, an integrated monitoring model based on maximum entropy theory is established. At the end of this paper, three monitoring models are used for the seepage monitoring of a measuring point of an earth-rock dam influenced by rainstorms, and the results show that the three monitoring models obtain satisfactory predication accuracy.

\section{Introduction}

Due to the characteristics of low cost, fine environmental adaptability, and lower construction difficulty, earth-rock dams have been widely used and rapidly developed in the world, which make up over 80 percent of all dams [1]. During the construction and running period of earth-rock dams, safety problems such as seepage [2], cracks [3], and landslide [4] may happen. Seepage has considerable influence on earthrock dams and often increases from small range to large range, which may cause dam settlement, collapse, and concentrated leakage passage for earth-rock dams. The structural damage may be a single form or multiple forms of damage in one part or different parts of the earth-rock dams. For the earth-rock dams in coastal areas suffer from rainstorms, the rapidly increased reservoir water lever and large amount of rain within a short time may cause threatened structural problems. Therefore, it is of great significance to study the seepage status of earth-rock dams influenced by rainstorms. Because earth-rock dams and the surrounding environment are rather complex and fickle, the potential seepage diseases are difficult to find out. Seepage monitoring analysis [5] of earth-rock dams could help to judge the existence of seepage damage and grasp the running status of earth-rock dams, which provides basis for the safety running of earth-rock dams.

To monitor and analyze the seepage status of earth-rock dams influenced by rainstorms accurately and timely, seepage monitoring models should be built up to help to find out seepage diseases conveniently and ensure the stable operation of the dams $[5,6]$. The influence factors concerning earth-rock dam seepage are the reservoir water level, precipitation, temperature, timeliness, and so forth. In fact, the influence of the reservoir water level and precipitation on earth-rock dam 
seepage exhibits hysteretic effect. Moreover, rainstorms may lead the reservoir water level to exceed the historical highest water level, which causes new deformation or even plastic deformation of earth-rock dams. Then, the permeability property of earth-rock material would change, which influences the seepage state of earth-rock dams. The exceeded reservoir water level factor is put forward to consider the abrupt increased reservoir water level.

Therefore, the seepage statistical model considering the hysteretic effect of reservoir water level and precipitation and the exceeded water level factor is established. Meanwhile, the influence factors on seepage monitoring indexes are rather complex, which make it difficult to simulate with explicit function. Artificial wavelet neural network [7-9] is the implicit function, which has the advantage to explain complex relationship. Thus, earth-rock dam seepage monitoring model based on artificial wavelet neural network is established. Based on the two monitoring models and maximum entropy theory [10-12], an integrated seepage monitoring model is set up to optimize the earth-rock dam seepage monitoring further. Finally, the three seepage monitoring models are applied to analyze the seepage status of an earth-rock dam influenced by rainstorms. The results show the three models with fine precision successfully used in earth-rock dam seepage monitoring, which provide technical support for seepage monitoring of other earth-rock dams.

\section{Earth-Rock Dam Seepage Statistical Model considering the Hysteretic Effect of Reservoir Water Level and Precipitation and the Exceeded Water Level Factor}

The most influential factors concerning earth-rock dam seepage include reservoir water level, precipitation, temperature, and timeliness. Given that the effect of reservoir water level and precipitation on seepage has the hysteretic effect, in the traditional seepage statistical model, the previous reservoir water level and precipitation are categorized based on averages over a number of previous days [5], for example, the previous two days, the previous five days, and the previous ten days. Practice has proven that the influences of reservoir water level and precipitation on seepage rise in the first stage and then decrease, which are presented as normal distribution [5]. The normal distribution curve is used to simulate the hysteretic effect, and the hysteretic days and influence days of reservoir water level and precipitation influence on earthrock dam seepage are hard to determine. Considering the efficiency of general calculation methods is low, quantum genetic algorithm $[13,14]$ is used to calculate the hysteretic days and influence days to obtain the optimal earth-rock dam seepage statistical model. Moreover, due to the influence of rainstorms, the reservoir water level may exceed the historical highest water level. As a result, the abrupt increased reservoir water level is difficult to simulate. Hence, the exceeded water level factor is added.

2.1. Reservoir Water Level Component. For the seepage index, we take the piezometric tube level as an example. The piezometric tube level is hysteretic influenced by the reservoir water level, and the seepage index at the time $t$ is given as follows:

$$
\begin{aligned}
& h(t)=F\left[t, H(t), H\left(t-\tau_{1}(t)\right), H\left(t-\tau_{2}(t)\right), \ldots,\right. \\
& \left.H\left(t-\tau_{n}(t)\right)\right],
\end{aligned}
$$

where $\tau$ is the retardation time, $\tau_{k}(t) \geq 0, k=1,2, \ldots, n$, and $H(t)$ and $H\left(t-\tau_{n}(t)\right)$ are the reservoir water level at the corresponding time.

Equation (1) reflects the hysteretic relationship between the reservoir water level and the piezometric tube level, and the piezometric tube level at the time $t$ is continuously influenced by the previous reservoir water level. Because the hysteretic time is difficult to determine, the previous reservoir water level is often categorized based on averages over a number of previous days, for example, the previous two days, the previous five days, and the previous ten days. However, these factors are fuzzy and are unable to accurately reflect the hysteretic effect of reservoir water levels. Moreover, the influence of the reservoir water level on the piezometric tube level may be from the previous two days, the previous ten days, or longer.

Suppose that the seepage index is influenced by the reservoir water level from the previous $n$ days $H_{i}(i=1,2, \ldots, n)$, and the equivalent water level $H_{d}$ is expressed as follows:

$$
H_{d}=\varphi\left(H_{1}, H_{2}, \ldots, H_{k}, \zeta_{1}, \zeta_{2}, \ldots, \zeta_{k}\right),
$$

where $\zeta_{i}, i=1,2, \ldots, k(k \leq n)$ is the weight of the $i$ th water level's influence on the equivalent water level and $\varphi$ is the function reflecting the hysteretic influence of the reservoir water level on the seepage index.

Considering the characteristic of the weight vector $\zeta=$ $\left[\zeta_{1}, \zeta_{2}, \ldots, \zeta_{k}\right]$, the following equation is then obtained:

$$
\sum_{i=1}^{k} \zeta_{i}=1, \quad k \leq n .
$$
follows:

Therefore, the equivalent water level $H_{d}$ is obtained as

$$
H_{d}=\sum_{i=1}^{k} \zeta_{i} H_{i}
$$

Numerous studies have shown that $\zeta(t)$ presents a normal distribution [5]. Combined with the characteristics of normal distributions, the hysteretic days and influenced days are set as $x_{1}$ and $x_{2}$. The process that describes the influence of the reservoir water level on the seepage index is shown in Figure 1, and the hysteretic influence function is given as follows:

$$
\zeta(t)=\frac{1}{\sqrt{2 \pi} x_{2}} e^{-\left(t-x_{1}\right)^{2} / 2 x_{2}^{2}} .
$$

If a water storage starts at the time $t_{0}$, then, at the fixed time $t_{1}$, the following equation is obtained:

$$
\int_{t_{0}}^{t_{1}} \zeta(t) d t=1
$$




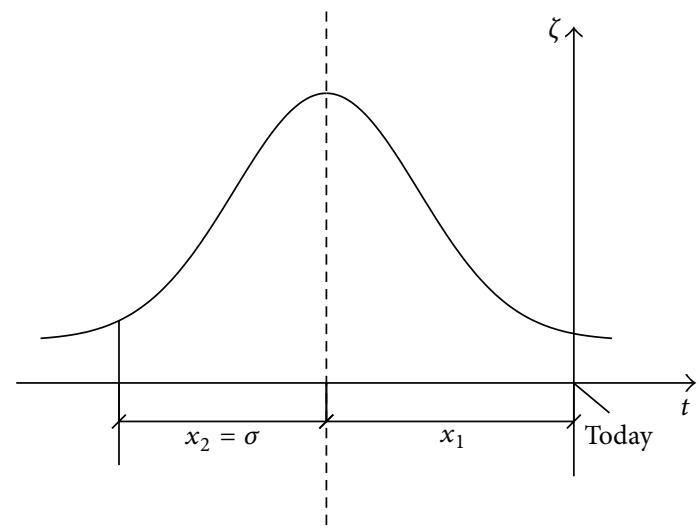

FIgURE 1: Normal distribution curve of the hysteretic water level.

For the piezometric tube level at a specific measuring point during a certain period of time, the hysteretic days $x_{1}$ and influenced days $x_{2}$ are constant.

$\zeta(t)$ in (5) can be treated as a function reflecting the influence of the previous water level on the equivalent water level $H_{d}$. Suppose that the equivalent reservoir water level at the time $t_{1}$ is $H_{d}$ and that the influenced weight function $\zeta(t) \geq 0$. Then, the following equation is obtained:

$$
\begin{aligned}
H_{d} & =\int_{t_{0}}^{t_{1}} \zeta(t) H(t) d t \\
& =\int_{t_{0}}^{t_{1}} \frac{1}{\sqrt{2 \pi} x_{2}} e^{-\left(t-x_{1}\right)^{2} / 2 x_{2}^{2}} H(t) d t,
\end{aligned}
$$

where $x_{1}$ is the undetermined hysteretic reservoir water level days, $x_{2}$ is the undetermined influenced normal distribution standard deviation, and $H(t)$ is the reservoir water level at the time $t$.

Quantum genetic algorithm is used to obtain the hysteretic days and influenced distributed parameter. Generally, the continuous integration is replaced by a discrete integration, and an integration range with the value of 3-4 times $x_{2}$ meets the accuracy requirements.

2.2. Precipitation Component. To reasonably consider the hysteretic effects of precipitation on earth-rock dam seepage, a lognormal distribution function is used to depict the precipitation effect on the earth-rock dam seepage. Specifically, the hysteretic influencing function of precipitation is given as follows:

$$
w(t)=\frac{1}{\sqrt{2 \pi} x_{4} t} e^{-\left(\ln t-x_{3}\right)^{2} / 2 x_{4}^{2}},
$$

where $x_{3}$ is the hysteretic days of precipitation and $x_{4}$ is the influencing distribution parameter.

Suppose that the observation day is $t_{1}$ and that the starting day is $t_{0}$. The influence range can be 1-2 months, and then,

$$
\int_{t_{0}}^{t_{1}} w(t) d t=1
$$

Similarly, an exponential transformation is adopted for the influence of precipitation infiltration. Suppose that the equivalent precipitation at the time $t_{1}$ is $P_{d}$. The hysteretic influenced function of precipitation meets the following condition:

$$
\begin{aligned}
P_{d} & =\int_{t_{0}}^{t_{1}} w(t)[P(t)]^{\beta} d t \\
& =\int_{t_{0}}^{t_{1}} \frac{1}{\sqrt{2 \pi} x_{4} t} e^{-\left(\ln t-x_{3}\right)^{2} / 2 x_{4}^{2}}[P(t)]^{\beta} d t,
\end{aligned}
$$

where $P(t)$ is the precipitation at the time of $t, \beta$ is the infiltration transformation index, $0<\beta<1$, and the remaining symbols have the same meaning as in (8).

Therefore, the precipitation component is expressed as follows:

$$
h_{P}=b P_{d}=b \int_{t_{0}}^{t_{1}} \frac{1}{\sqrt{2 \pi} x_{4} t} e^{-\left(\ln t-x_{3}\right)^{2} / 2 x_{4}^{2}}[P(t)]^{\beta} d t,
$$

where $h_{P}$ is the precipitation component, $b$ is the regression coefficient, $x_{3}$ is the undetermined hysteretic days of precipitation, $x_{4}$ is the undetermined distributed parameter of precipitation, $P(t)$ is the precipitation at the time of $t$, and $P_{d}$ is the equivalent precipitation.

Similarly, quantum genetic algorithm is used to optimally obtain $x_{3}$ and $x_{4}$.

2.3. Temperature Component. Although seepage has no direct relation with the water temperature, air temperature, and batholith temperature, the temperature variation changes the viscosity of water and the batholith crack opening: as a result, the seepage status may change. The temperature component of seepage is mainly caused by the temperature variations in the dam foundation and the batholith on both sides of the dam, and the temperature variation exhibits annual periodic variations or semiannual periodic variations. However, sufficient measured temperature data have not been provided. Therefore, a temperature component consisting of sine and cosine functions with periods of a year and half a year is given as follows:

$$
h_{T}=\sum_{i=1}^{n}\left(c_{1 i} \sin \frac{2 \pi i t}{365}+c_{2 i} \cos \frac{2 \pi i t}{365}\right) \quad i=1,2,
$$

where $i=1,2$ corresponds to the period of a year and half a year, $n=2$, and $c_{1 i}$ and $c_{2 i}$ are the regression coefficient.

2.4. Timeliness Component. During operation of the earthrock dam, the structure of soil grains may change. Meanwhile, the gradually produced deposit in front of the dam forms a natural blanket. The influence of these factors on the seepage exhibits the timeliness process and can be modeled using the following equation:

$$
h_{\theta}=d_{1} \theta+d_{2} \ln \theta,
$$

where $d_{1}$ and $d_{2}$ are the regression coefficients of the timeliness component and $\theta$ is the cumulative number of days from the starting day to the measured day dividing 100 . 
2.5. Exceeded Eater Level Factor. For earth-rock dams influenced by rainstorms, the reservoir water level may exceed the previous historical highest water level. The reservoir water level is unable to accurately reflect abrupt increases in the reservoir water level. If the reservoir water level for a certain day exceeds the previous historical highest water level, the exceeded water level factor is used. The factor relates to the excess of the reservoir water level, the reservoir water level on the day of operation, and the rate of change of the water level. The greater the excess reservoir water level is, the greater the influence on the earth-rock dam seepage will be. Therefore, the exceeded water level factor is given as follows:

$$
h_{e}=\sum_{i=1}^{2}\left[e_{i}\left(\mathrm{DH}_{i}\right)\right]+\left.\sum_{j=1}^{3} f_{i} \frac{\Delta H}{\Delta t}\right|_{\Delta t=j},
$$

where $\mathrm{DH}_{1}$ is the excess reservoir water level, $\mathrm{DH}_{2}$ is the product of $\mathrm{DH}_{1}$ and the water level $H$ on the measuring day, and $\Delta H / \Delta t$ is the rate of change over the previous $i$ days.

2.6. Earth-Rock Dam Seepage Statistical Model. By studying the earth-rock dam seepage statistical model considering the hysteretic effect of precipitation and reservoir water level and the exceeded water level factor, combined with the temperature component and timeliness component, the earth-rock dam seepage statistical model is obtained as follows:

$$
\begin{aligned}
H= & h_{H}+h_{P}+h_{T}+h_{\theta}+h_{e} \\
= & A_{0}+a H_{d}+b P_{d} \\
& +\sum_{i=1}^{n}\left(c_{1 i} \sin \frac{2 \pi i t}{365}+c_{2 i} \cos \frac{2 \pi i t}{365}\right)+d_{1} \theta \\
& +d_{2} \ln \theta+\sum_{i=1}^{2}\left[e_{i}\left(\mathrm{DH}_{i}\right)\right]+\left.\sum_{j=1}^{3} f_{i} \frac{\Delta H}{\Delta t}\right|_{\Delta t=j},
\end{aligned}
$$

where $A_{0}$ is a constant term and the other parameters have the same meaning as mentioned above.

By selecting multiple correlation coefficients or the residual standard deviation as the objective function, the quantum genetic algorithm is used to obtain the optimal hysteretic parameters and the coefficient in (15). The calculation procedure is shown in Figure 2.

\section{Earth-Rock Dam Seepage Monitoring Model Based on Artificial Wavelet Neural Network}

The relationship between environment factors and earth-rock dam seepage is rather complex, and it is difficult for an explicit function to simulate this complex relationship. Artificial neural network algorithm is a type of implicit function with strong nonlinear fitting ability and adaptability. The wavelet transformation has the ability to better analyze the local details of the measured data and reflects the characteristics of the measured data. Therefore, combined with wavelet analysis and the artificial neural network algorithm, an earth-rock dam seepage monitoring model based on the artificial wavelet neural network is established.

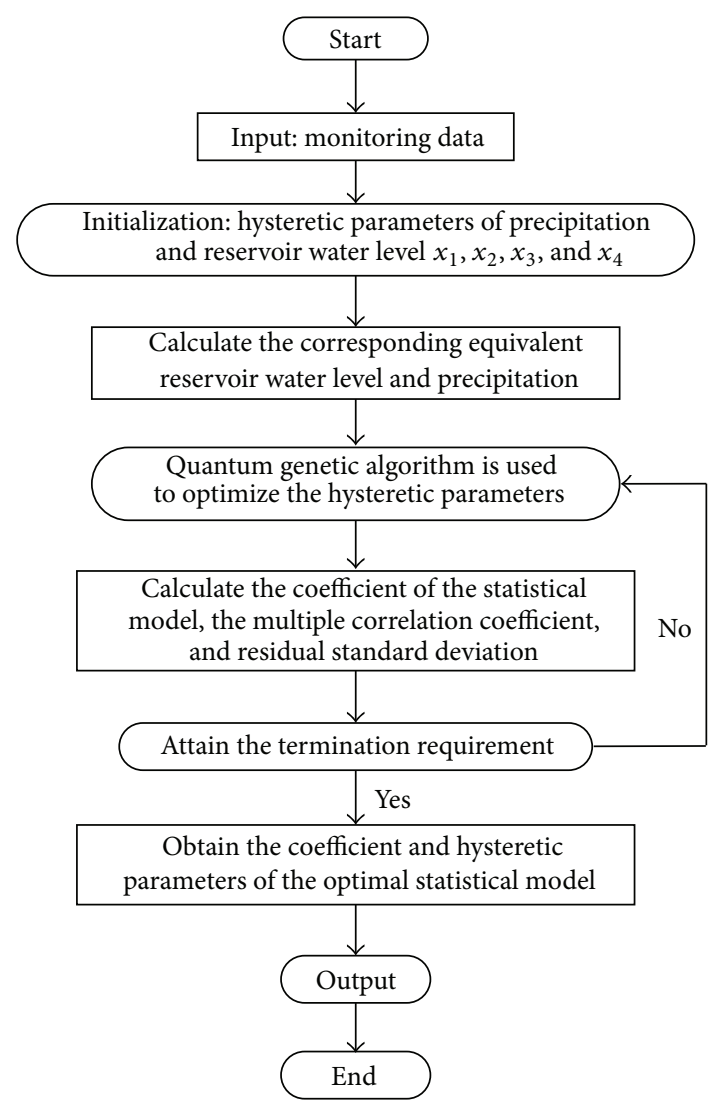

FIGURE 2: Calculation process of the optimal earth-rock dam seepage statistical model.

3.1. Wavelet Theory. Wavelet analysis $[15,16]$ is a type of multiresolution data analysis method with the ability to analyze any details of an object. Through wavelet analysis, a signal is resolved into different frequency bands. Supposing that the wavelet function $\varphi(t)$ transforms with a magnitude of $\tau$, the inner product between the original signal $x(t)$ and the wavelet function using a scaling of $a$ is obtained as follows:

$$
f_{x}(a, \tau)=\frac{1}{\sqrt{a}} \int_{-\infty}^{+\infty} x(t) \varphi\left(\frac{t-\tau}{a}\right) d t \quad a>0 .
$$

Through the transformation of the wavelet basis function and the analysis of the local features of the signal, the local characteristics of the seepage data are obtained, which help to reflect the multiscale change law of the measured data.

\subsection{Earth-Rock Dam Seepage Monitoring Model Based on} Artificial Wavelet Neural Network. Because it fuses the artificial neural network algorithm and wavelet theory, artificial wavelet neural networks have the advantage of providing multiscale analysis and implicit function. Therefore, the seepage monitoring model based on the artificial wavelet neural network more objectively reflects the seepage status. The transfer function of the nodes in the hidden layer of the neural network is the wavelet basis function. The weight value and threshold value are adjusted through error back 


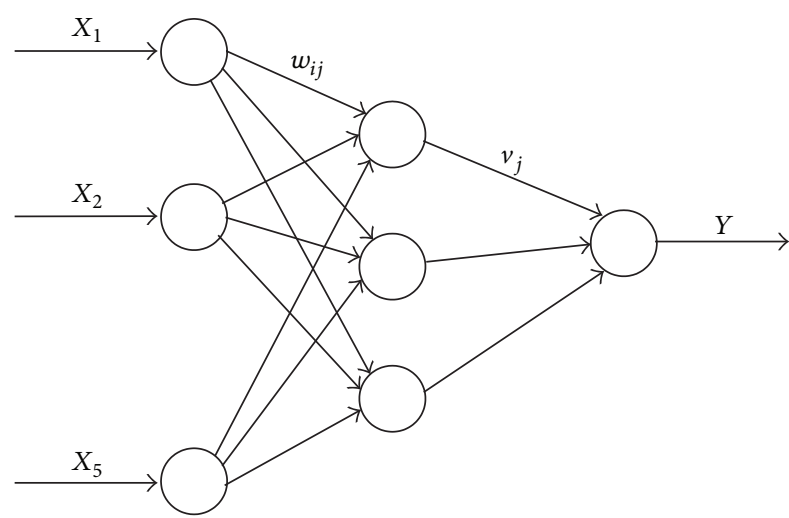

FIGURE 3: Topological structure of artificial wavelet neural network.

propagation. Figure 3 shows the topological structure of the artificial wavelet neural network.

In Figure $3, X_{i}(i=1,2, \ldots, 5)$ are the input factors, which correspond to the reservoir water level component, precipitation component, temperature component, timeliness component, and the exceeded water level factor. $Y$ is the output value, that is, the seepage index, and $w_{i j}$ and $v_{j}$ are the weight values.

The data series of input factors are $X_{i}(i=1,2, \ldots, 5)$, and the output in the hidden layer is

$$
h(j)=h_{j}\left[\frac{\sum_{i=1}^{4} w_{i j} X_{i}-b_{j}}{a_{j}}\right] \quad j=1,2, \ldots, l,
$$

where $h(j)$ is the output value of the $j$ th node in the hidden layer, $w_{i j}$ is the weight between the input layer and the hidden layer, $h_{j}$ is the wavelet basis function, $b_{j}$ is the shift factor of the wavelet basis function, and $a_{j}$ is the scaling factor of the wavelet basis function.

As the excitation function in the network, the selection of wavelet function is very important to the fitting and predicated results. Since Morlet wavelet has the characteristic of calculation stability, small error, and fine robustness on error interference, a Morlet wavelet [17] with the function image shown in Figure 4 is used in the artificial wavelet neural network, and its specific formula is given as follows:

$$
h(x)=\cos (1.75 x) e^{-x^{2} / 2}
$$

Then, the output of the seepage index is

$$
Y=\sum_{j=1}^{l} v_{j} h(j)
$$

where $Y$ is the exporting seepage index and the other parameters are similar to those in (17) and (18) and Figure 4.

The gradient descent method is used to modify the weights in the artificial wavelet neural network, through which the output values gradually approach the expectation

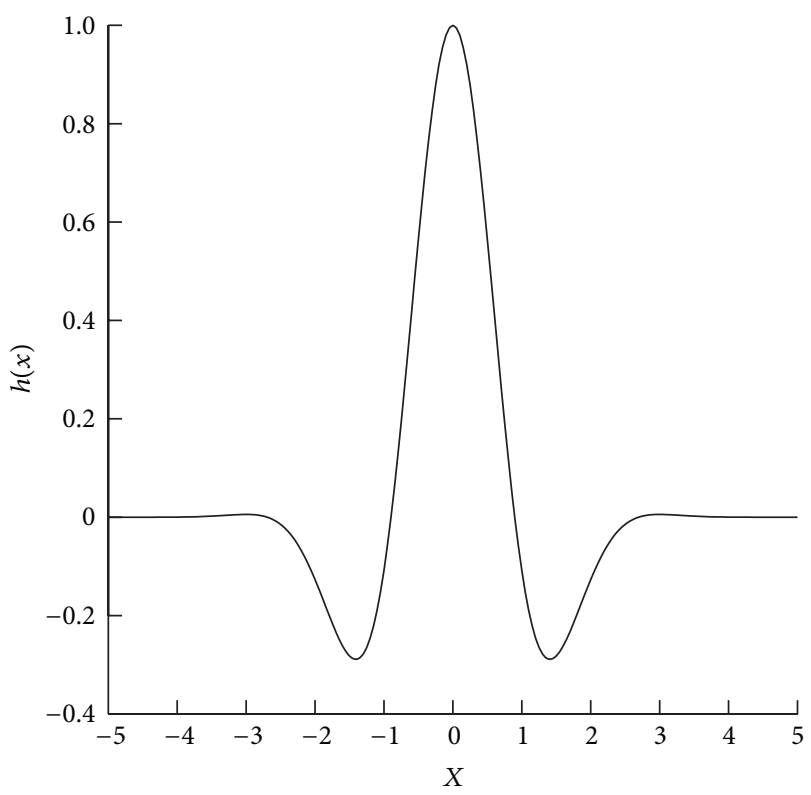

Figure 4: Morlet wavelet function.

until the termination condition is satisfied. The concrete steps are given as follows:

(1) Parameter initialization: the scaling factor $a_{j}$, the shift factor $b_{j}$, and the weights $w_{i j}$ and $w_{j k}$ are initialized randomly, and the learning rate $\eta$ and the momentum coefficient $\alpha$ are selected appropriately.

(2) Classification of original samples: the original samples are classified as either the training set or the test set. The training set is used to train the network, and the test set is used to test the network.

(3) Comparison of output values: the test set is imported into the network, and the mean squared error $e$ is obtained by subtracting the predicted output from the expected output as follows:

$$
e=\frac{1}{N} \sum_{i=1}^{N}(Y-\widehat{Y})^{2}
$$

where $\widehat{Y}$ is the expected output and $N$ is the sample size.

(4) Modification of weight: based on the error $e$, the gradient descent method is used to modify the weight, scaling factor, and shift factor to make the predicted output approximate the expected output.

(5) Convergence judgment: when the computation is converged, the computation is halted. Otherwise, the computation should return to Step (3), and the network parameters should be adjusted as follows:

$$
\begin{aligned}
\Delta w_{i j}{ }^{n+1} & =-\eta \frac{\partial e}{\partial w_{i j}{ }^{t}}+\alpha \Delta w_{i j}{ }^{n}, \\
\Delta a_{j}{ }^{n+1} & =-\eta \frac{\partial e}{\partial a_{j}{ }^{t}}+\alpha \Delta a_{j}{ }^{n}, \\
\Delta b_{j}{ }^{n+1} & =-\eta \frac{\partial e}{\partial b_{j}{ }^{t}}+\alpha \Delta a_{j}{ }^{n},
\end{aligned}
$$


where $\Delta w_{i j}{ }^{n}, \Delta a_{j}{ }^{n}$, and $\Delta a_{j}{ }^{n}$ are the changes in the network parameters in the $n$th iteration.

In addition,

$$
\begin{gathered}
w_{i j}{ }^{n+1}=w_{i j}{ }^{n}+\Delta w_{i j}{ }^{n+1}, \\
a_{j}^{n+1}=a_{j}{ }^{n}+\Delta a_{j}{ }^{n+1}, \\
b_{j}^{n+1}=b_{j}^{n}+\Delta b_{j}^{n+1},
\end{gathered}
$$

where $w_{i j}{ }^{t}, a_{j}{ }^{t}$, and $b_{j}{ }^{t}$ are the network parameters in the $n$th iteration.

The weight and valve values are modified until the terminal condition is satisfied. The finally obtained parameters are substituted into the artificial wavelet neural network and combined with the import of reservoir water level component, precipitation component, temperature component, timeliness component, and the exceeded water level factor; the seepage index series are then exported. Finally, the monitoring model based on the artificial wavelet neural network is obtained and can be used to monitor earth-rock dam seepage.

\section{The Integrated Earth-Rock Dam Seepage Monitoring Model Based on Maximum Entropy Theory}

The two above-mentioned earth-rock dam seepage monitoring models mentioned above have their own strengths and weaknesses. Through the consideration of the hysteretic effect of seepage and the exceeded water level factor, the statistical model reflects the seepage status of the earth-rock dam to a certain extent. However, a reasonable explicit function that reflects the complex influencing factors of seepage is difficult to select. Artificial wavelet neural network helps to address this difficulty and is quite capable of determining the local details of measured data. Simultaneously, the artificial wavelet neural network suffers from artificial factors. Therefore, based on the application of maximum entropy theory, to obtain the advantages of the two above-mentioned monitoring models mentioned, the integrated earth-rock dam seepage model is established. This model is of great significance to the monitoring of the seepage status of earth-rock dams.

Maximum entropy theory originates from classical thermodynamics, which is an important theory in the frontier of modern physics. Entropy is applied to information theory, which has been successfully applied to different subject areas. Specifically, the expression of entropy is given as follows:

$$
S(x)=-\sum_{i=1}^{n} p_{i} \ln p_{i}
$$

where $p_{i}$ is the probability that the signal $x_{i}$ appears in a signal source and $S(x)$ is the magnitude of the entropy, which measures the uncertainty of the system status.

Under the given condition, to solve an ill-posed problem, one probability distribution among all possible probability distributions is found to have the maximum value of entropy.
For the seepage index of earth-rock dams, the optimization problem in maximum entropy theory is given as follows:

$$
\max S(X)=-\sum_{i=1}^{n} p_{i} \ln p_{i}
$$

In addition, the constraint condition is

$$
\begin{gathered}
\sum_{i=1}^{n} f_{k}\left(x_{i}\right) p_{i}=F_{k} \quad k=1,2, \\
\sum_{i=1}^{n} p_{i}=1 \quad p_{i} \geq 0 .
\end{gathered}
$$
holds:

When the entropy is maximized, the following equation

$$
p_{i}=\exp \left[\lambda_{0}+\sum_{k=1}^{2} \lambda_{k} f_{k}\left(x_{i}\right)\right] \quad i=1,2, \ldots, n,
$$

where $S(X)$ is the entropy of the seepage index, $p_{i}$ is the probability when the value of the seepage index $X$ is $x_{i}, f_{k}\left(x_{i}\right)$ is a function, such as the first-order central moment and second-order central moment, of $X, F_{k}$ is the mean value of $f_{k}\left(x_{i}\right), \lambda_{k}$ are Lagrange multiplier, $k=1$ corresponds to the earth-rock dam seepage statistical model, and $k=$ 2 corresponds to the earth-rock dam seepage monitoring model based on the artificial wavelet neural network.

The seepage index of earth-rock dams can be regarded as a discrete series continuously changing time, which is used in the two monitoring models to obtain predicted values and the difference between the predicted value and the measured value. With the obtained results regarding the constrained information of the predictor, maximum entropy theory is applied to solve the constraint information problem to improve the precision of the model predication. The concrete calculation steps are given as follows.

(1) Calculation of Model Eigenvalues. To obtain information about the earth-rock dam seepage statistical model and the earth-rock dam seepage monitoring model based on the artificial wavelet neural network, eigenvalues of the computation results of the models are obtained. Suppose that $N$ measured values are provided and the $i$ th measured data set is $x_{i}(i=$ $1,2, \ldots, N)$, and the calculated values of the seepage index based on the two monitoring models are $\hat{x}_{i k}(k=1,2)$. The variance of the calculated values based on the two models is

$$
e_{k}=\frac{1}{N} \sum_{i=1}^{N}\left(\frac{x_{i}-\widehat{x}_{i k}}{\widehat{x}_{i k}}\right)^{2} \quad k=1,2
$$

(2) Solution of the Probability Density Function Based on Maximum Entropy. The earth-rock dam seepage index $X$ is a discrete random variable, and the following equation based on maximum entropy theory is given:

$$
\max S(X)=-\sum_{i=1}^{N} p_{i} \ln p_{i}
$$


The constraint condition is

$$
\begin{aligned}
\sum_{i=1}^{N}\left(\frac{x_{i}-\hat{x}_{i k}}{\widehat{x}_{i k}}\right)^{2} p_{i} & =e_{k}, \\
\sum_{i=1}^{N} p_{i} & =1 \quad p_{i} \geq 0 .
\end{aligned}
$$

Substituting (26) into (29),

$$
\begin{aligned}
\sum_{i=1}^{N}\left(\frac{x_{i}-\hat{x}_{i k}}{\hat{x}_{i k}}\right)^{2} \exp \left[\lambda_{0}+\sum_{k=1}^{2} \lambda_{k}\left(\frac{x_{i}-\hat{x}_{i k}}{\widehat{x}_{i k}}\right)^{2}\right] & =e_{k}, \\
\sum_{i=1}^{N} \exp \left[\lambda_{0}+\sum_{k=1}^{2} \lambda_{k}\left(\frac{x_{i}-\widehat{x}_{i k}}{\hat{x}_{i k}}\right)^{2}\right] & =1 .
\end{aligned}
$$

Combining (30) and (31), the Lagrange multipliers $\lambda_{0}$ and $\lambda_{k}(k=1,2)$ are obtained, and the probability function of the $i$ th measured value is

$$
p\left(X=x_{i}\right)=\exp \left[\lambda_{0}+\sum_{k=1}^{2} \lambda_{k}\left(\frac{x_{i}-\widehat{x}_{i k}}{\hat{x}_{i k}}\right)^{2}\right] .
$$

(3) Prediction of Seepage Index. For the seepage index in the upcoming $T$ days, the predicated results of the $t$ th $(t=1,2, \ldots, T)$ seepage index based on the two monitoring models are $\hat{x}_{t k}(k=1,2)$, and the probability of the $t$ th predicated seepage index is

$$
p\left(X=x_{t}\right)=\exp \left[\lambda_{0}+\sum_{k=1}^{2} \lambda_{k}\left(\frac{x_{i}-\widehat{x}_{i k}}{\hat{x}_{i k}}\right)^{2}\right] .
$$

By integrating the probability, the desired value, which is the predicated value on the $t$ th day, is obtained. Then, repeating Step (3), the predicated series of the $T$ seepage monitoring values of the earth-rock dam is obtained.

\section{Case Study}

5.1. Project Profile. To verify the three models applied to the monitoring of the earth-rock dam seepage status, we take a reservoir located in Zhejiang, China, for analysis. The reservoir is an integrated large reservoir, which has the functions of flood protection, water supply, irrigation, and electricity generation. It controls drainage area of 258 square kilometers and has a total storage of 114 million cubic meters. The normal water level and the maximum flood level are $115.127 \mathrm{~m}$ and $123.527 \mathrm{~m}$. The project consisted of diversion dam, normal spillway, emergency spillway, flood diversion sluice, water supply tunnel, and power station. The reservoir dam is Clay Core Wall Sand Dam, with the top elevation of dam, top elevation of wave wall, maximum dam height, width of dam crest, and length of dam crest being $124.527 \mathrm{~m}, 125.727 \mathrm{~m}$, $36.9 \mathrm{~m}, 6 \mathrm{~m}$, and $560 \mathrm{~m}$, respectively. The upstream slope and downstream slope of the dam are 1:2.0-2.80 and 1:1.85-2.0.

Every year, there is abundant rain around the reservoir. Sometimes the reservoir suffered from rainstorm. In the period between 1 January 2012 and 31 December 2013,

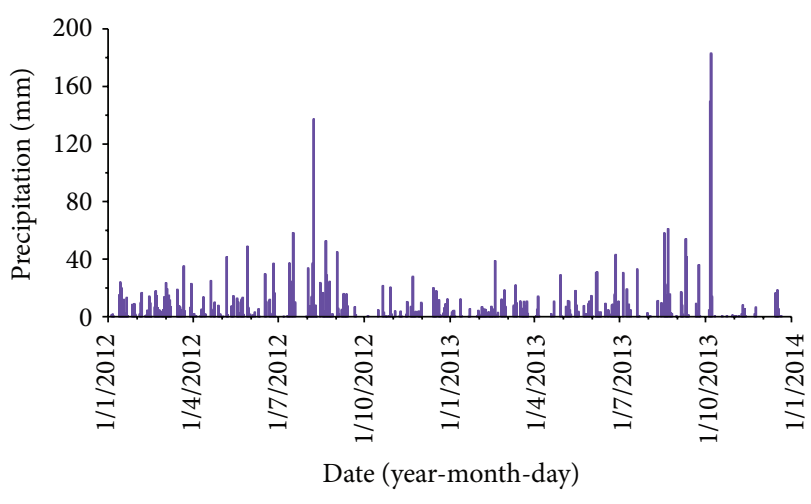

Precipitation

FIGURE 5: Monitoring data of precipitation (mm).

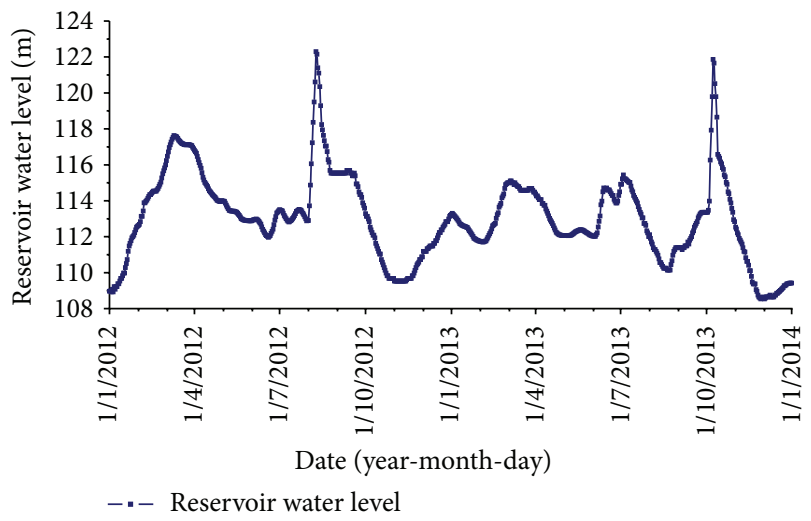

FIGURE 6: Monitoring data of reservoir water level (m).

the reservoir suffered from rainstorm due to the influence of Typhoon Haikui which happened in August 2012 and Typhoon Fitow which happened in October 2013, and the maximum precipitation in one day is $137.2 \mathrm{~mm}$ and $183.0 \mathrm{~mm}$. The corresponding increased reservoir water levels are $8.43 \mathrm{~m}$ and $7.89 \mathrm{~m}$. After the rainstorm, the reservoir water level reduces gradually.

Therefore, we take the measuring point I- 1 in the cross section of $0-60.0$ of the earth-rock dam for analysis, and the measured interval of measuring point I-1 is 7 days. By setting the period between 1 July 2012 and 31 October 2013 as the modeling period, the three monitoring models are used to fit the piezometric tube level of the measuring point and predicate the seepage status of the measuring point between 1 November 2013 and 31 December 2013. Figures 5 and 6 show the monitoring data for precipitation and reservoir water level between 1 January 2012 and 31 December 2013, and their measured interval is 1 day.

\subsection{The Application of Three Models in Monitoring the Seepage Status}

5.2.1. Statistical Model considering the Hysteretic Effect of Reservoir Eater Level and Precipitation and the Factor of the Exceeded Water Level. Based on (15) and on the fitness function with the multiple correlation coefficients $R$, a quantum genetic algorithm with a population of 40 is used to 
TABLE 1: Statistical metrics of the statistical model.

\begin{tabular}{lcc}
\hline $\begin{array}{l}\text { Coefficient of } \\
\text { determination }\end{array}$ & $\begin{array}{c}\text { Root mean } \\
\text { square error }\end{array}$ & $\begin{array}{c}\text { Mean biased } \\
\text { error }\end{array}$ \\
\hline 0.934 & 0.422 & 1.043 \\
\hline
\end{tabular}

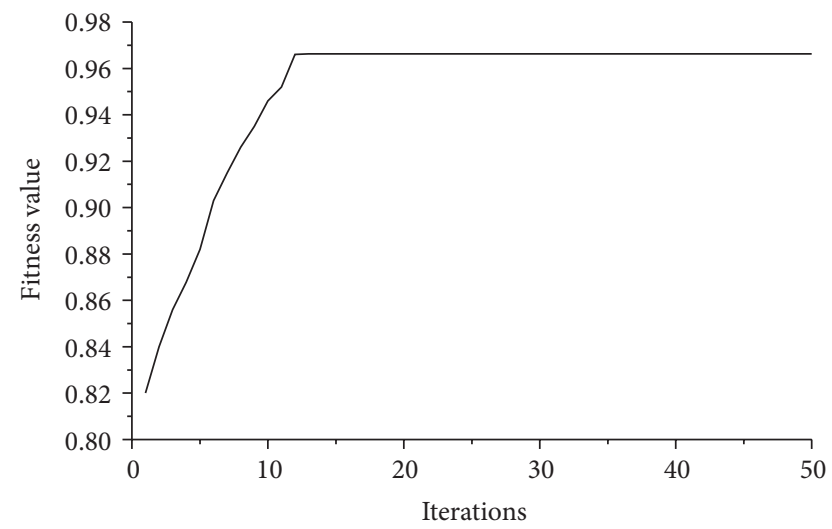

FIGURE 7: Iterative curve of quantum genetic algorithm.

optimize the hysteretic parameters of the reservoir water level and precipitation. Figure 7 illustrates the iterative curve of the quantum genetic algorithm, and the optimal multiple correlation coefficient is 0.966 . Table 1 shows the statistical metrics of the statistical model.

Through the solution obtained using the optimization algorithm, the hysteretic parameters $x_{1}, x_{2}, x_{3}$, and $x_{4}$ are 19 days, 16 days, 40 days, and 40 days, respectively. The equivalent reservoir water level and precipitation based on (7) and (11) are shown in Figures 8 and 9. Figure 10(a) illustrates the comparison between the fitting values and the measured values, and Figure 10(b) shows the scatter plot of measured versus fitted with regression line. As shown in Figures 10(a) and 10(b), we can clearly see how model behaves in lower and higher regions. Table 2 shows the coefficients of the model.

For the prediction series between 1 November 2013 and 31 December 2013, the predicted values and measured values of piezometric level are shown in Table 3.

5.2.2. Seepage Monitoring Model Based on Artificial Wavelet Neural Network. The input of the monitoring model based on the artificial wavelet neural network includes the equivalent reservoir water level, equivalent precipitation, temperature, timeliness, and the exceeded water level factor, and the output is the measuring point I-1 series. According to (15), 13 factors are input factors. By setting the number of network nodes of the hidden layer as 10, the topological structure of the network is $13-10-1$.

Since the measured interval of measuring point I-1 is 7 days, we select 7 days, 14 days, and 21 days as the sampling time to have the comparative analysis. Table 4 shows the mean squared error for the three cases, and the artificial wavelet neural network model with the sampling time of 7 days has the greater precision. Therefore, we select all the measured values of measuring point I-1 to have analysis.

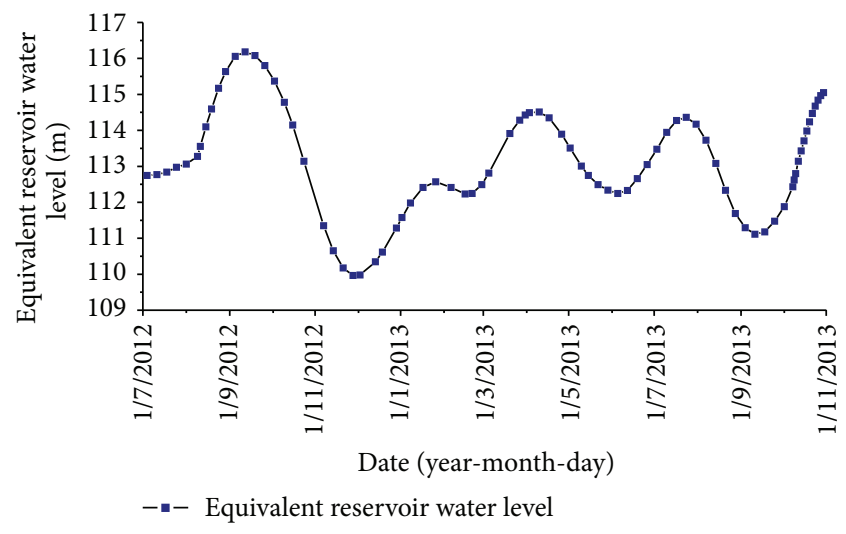

Figure 8: Equivalent reservoir water level (m).

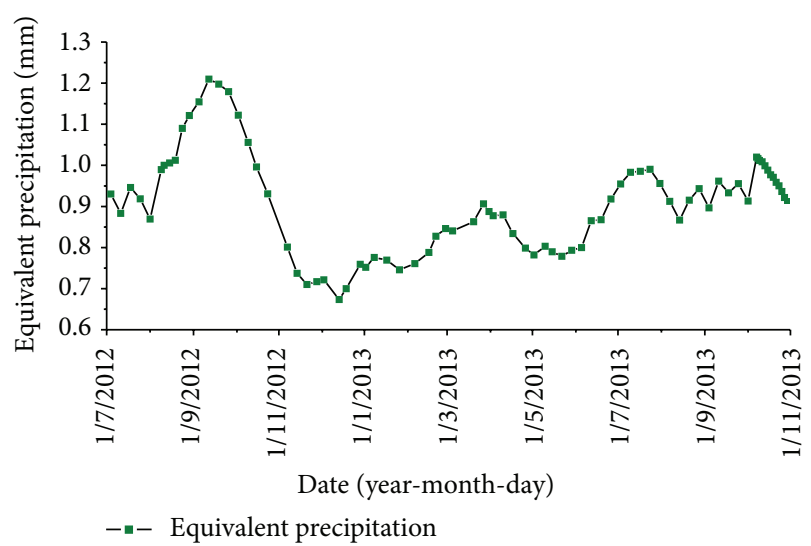

FIGURE 9: Equivalent precipitation (mm).

Figure 11 shows the mean squared error variability for the 30 epochs in the network training process using artificial wavelet neural network, and the minimum mean squared error is 0.426 . Figure 12(a) illustrates the comparison between the fitted values of the monitoring model based on the artificial wavelet neural network and measured values, and Figure 12(b) shows the scatter plot of measured versus fitted with regression line. As shown in Figures 12(a) and 12(b), we can clearly see how model behaves in lower and higher regions. Table 5 shows the predicated values and measured values of piezometric tube level.

In addition, Table 6 shows the coefficients of artificial wavelet neural network model. Through the comparison between the coefficients of the statistical model and the artificial wavelet neural network, we can see the statistical model has a higher precision as a whole.

5.2.3. The Integrated Seepage Monitoring Model Based on Maximum Entropy Theory. Based on maximum entropy theory, the Lagrangian multipliers $\lambda_{0}, \lambda_{1}$, and $\lambda_{2}$ are obtained through the solution of (28)-(32). $\lambda_{1}$ corresponds to the statistical model and $\lambda_{2}$ corresponds to the monitoring model based on the artificial wavelet neural network.

After applying the probability function, the predicated values in the predication period are obtained. Table 7 shows 


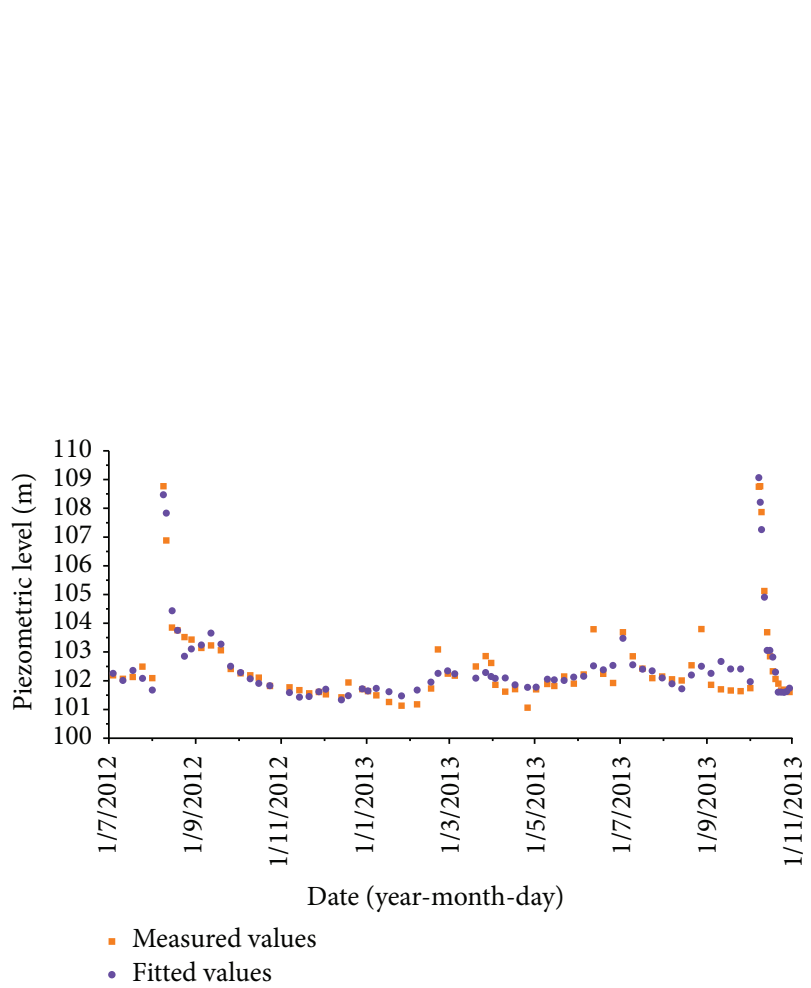

(a)

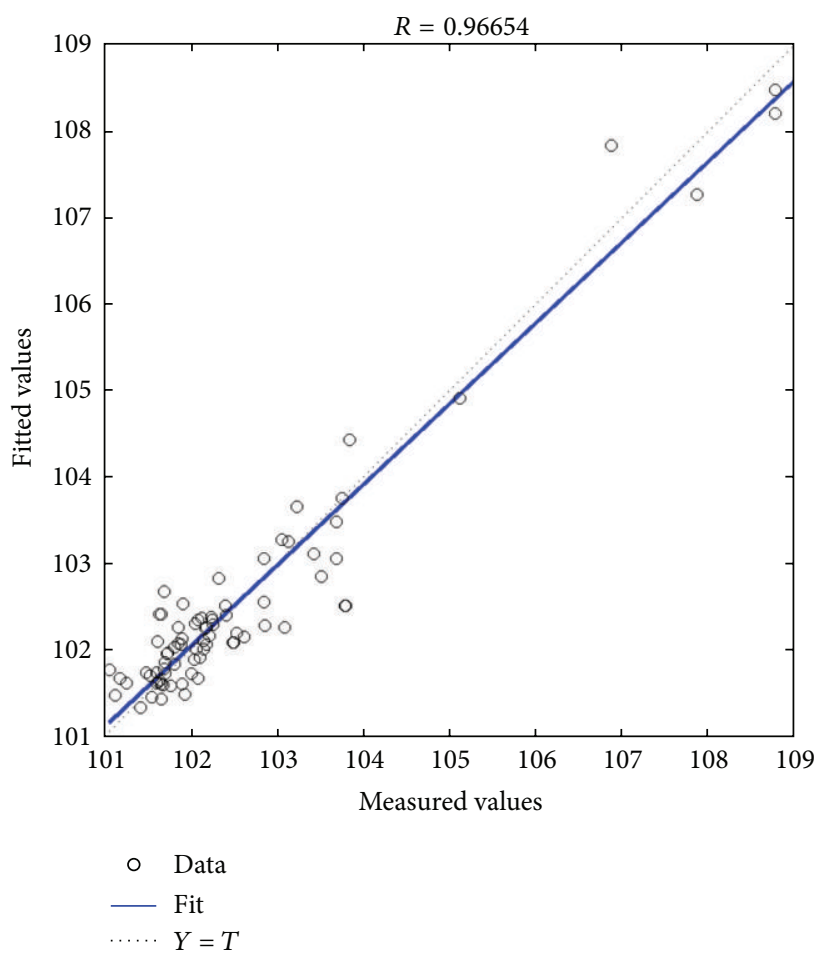

(b)

FIGURE 10: (a) Comparison between fitted values of the statistical model and measured values (mm) and (b) the scatter plot of measured versus fitted with regression line.

TABLE 2: Coefficients of the statistical model.

\begin{tabular}{lccccccc}
\hline Coefficients & $A_{0}$ & $a$ & $b$ & $c_{11}$ & $c_{21}$ & $c_{12}$ & $c_{22}$ \\
\hline Value & 130.968 & -0.308 & 6.465 & -344.32 & 75.351 & 52.705 & -35.038 \\
\hline Coefficients & $d_{1}$ & $d_{2}$ & $e_{1}$ & $e_{2}$ & $f_{1}$ & $f_{2}$ & $f_{3}$ \\
\hline Value & 387.371 & 0.399 & 0.708 & $4.304 e-5$ & 0.324 & -0.959 & 1.261 \\
\hline
\end{tabular}

TABLE 3: The predicated values of the statistical model.

\begin{tabular}{lcc}
\hline Date & Measured value & Fitted value \\
\hline $2013 / 11 / 6$ & 101.580 & 101.225 \\
$2013 / 11 / 27$ & 101.370 & 101.336 \\
$2013 / 12 / 18$ & 101.590 & 101.123 \\
$2013 / 11 / 13$ & 101.500 & 101.454 \\
$2013 / 12 / 4$ & 101.320 & 101.160 \\
$2013 / 12 / 25$ & 101.360 & 100.854 \\
$2013 / 11 / 20$ & 101.430 & 101.313 \\
$2013 / 12 / 11$ & 101.220 & 100.910 \\
\hline
\end{tabular}

TABLE 4: Mean squared error in the cases of different sampling time.

\begin{tabular}{lccc}
\hline Sampling time & 7 days & 14 days & 21 days \\
\hline Mean squared error & 0.426 & 0.613 & 0.768 \\
\hline
\end{tabular}

the predicated values of the integrated model based on maximum entropy theory.

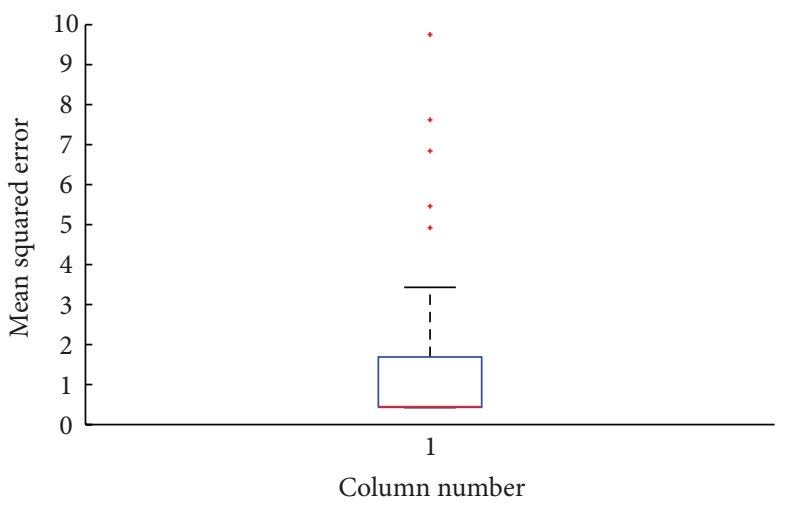

FIGURE 11: Mean squared error variability for 30 epochs in network training process by artificial wavelet neural network.

To compare the prediction precision of the three models, we show the statistical metrics of the predicated values of the three models in Table 8, and we find that the integrated monitoring model based on maximum entropy theory fuses 


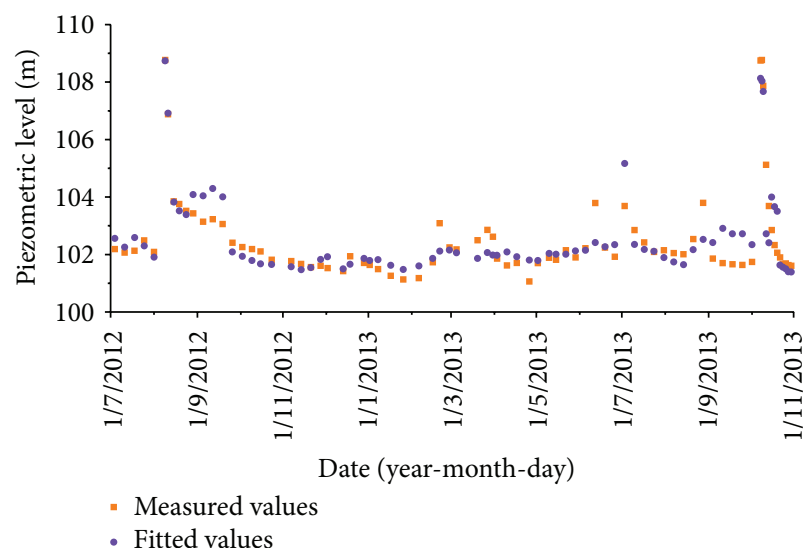

(a)

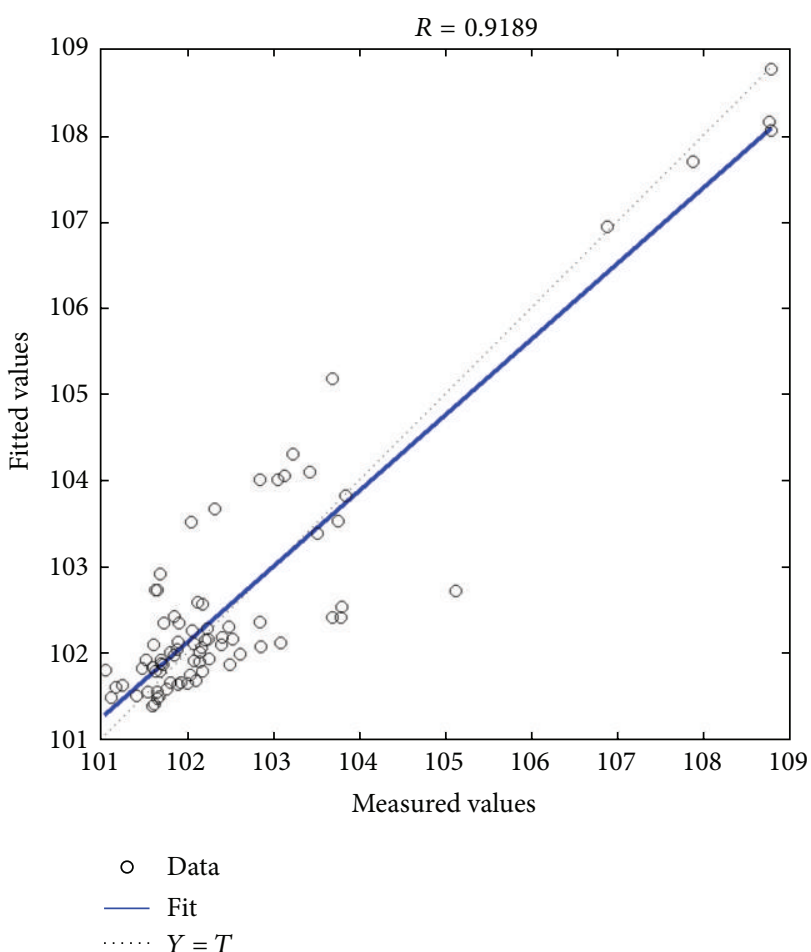

(b)

FIGURE 12: (a) Comparison between fitted values of the monitoring model based on artificial wavelet neural network and measured values and (b) the scatter plot of measured versus fitted with regression line.

TABLE 5: Comparison between predicated values of the monitoring model based on maximum entropy theory and measured values.

\begin{tabular}{lcc}
\hline Date & Measured value & Fitted value \\
\hline $2013 / 11 / 6$ & 101.580 & 101.897 \\
$2013 / 11 / 27$ & 101.370 & 101.574 \\
$2013 / 12 / 18$ & 101.590 & 101.070 \\
$2013 / 11 / 13$ & 101.500 & 102.139 \\
$2013 / 12 / 4$ & 101.320 & 101.382 \\
$2013 / 12 / 25$ & 101.360 & 101.060 \\
$2013 / 11 / 20$ & 101.430 & 101.313 \\
$2013 / 12 / 11$ & 101.220 & 101.137 \\
\hline
\end{tabular}

TABLE 6: Statistical metrics of the artificial wavelet neural network model.

\begin{tabular}{lcc}
\hline $\begin{array}{l}\text { Coefficient of } \\
\text { determination }\end{array}$ & $\begin{array}{c}\text { Root mean square } \\
\text { error }\end{array}$ & $\begin{array}{c}\text { Mean biased } \\
\text { error }\end{array}$ \\
\hline 0.843 & 0.652 & 0.964 \\
\hline
\end{tabular}

the advantages of the two models and thus obtains greater prediction accuracy.

\section{Conclusions}

This work studied the three monitoring models applied to the seepage status of earth-rock dams influenced by rainstorms. The main content of this paper was as follows:
TABLE 7: Comparison between predicated values of the integrated model and measured values.

\begin{tabular}{lcc}
\hline Date & Measured value & Fitted value \\
\hline $2013 / 11 / 6$ & 101.580 & 101.567 \\
$2013 / 11 / 27$ & 101.370 & 101.365 \\
$2013 / 12 / 18$ & 101.590 & 101.371 \\
$2013 / 11 / 13$ & 101.500 & 101.466 \\
$2013 / 12 / 4$ & 101.320 & 101.353 \\
$2013 / 12 / 25$ & 101.360 & 101.189 \\
$2013 / 11 / 20$ & 101.430 & 101.376 \\
$2013 / 12 / 11$ & 101.220 & 101.468 \\
\hline
\end{tabular}

TABLE 8: Statistical metrics of the predicated values of the three models.

\begin{tabular}{lcc}
\hline Model & $\begin{array}{c}\text { Root mean } \\
\text { square error }\end{array}$ & $\begin{array}{c}\text { Mean biased } \\
\text { error }\end{array}$ \\
\hline $\begin{array}{l}\text { Statistical model } \\
\text { Artificial wavelet neural } \\
\text { network model }\end{array}$ & 0.304 & 0.249 \\
Integrated model & 0.342 & 0.280 \\
\hline
\end{tabular}

(1) Based on the research on the hysteresis effect of reservoir water levels and precipitation, the reservoir water level and precipitation were equivalently processed to obtain equivalent reservoir water levels and 
precipitation. To easily simulate the rapidly increased reservoir water lever, the exceeded water level factor was introduced. Combined with the components of temperature and timeliness, a statistical model was established.

(2) By analyzing the characteristics of wavelet theory and neural networks, a monitoring model that fuses both wavelet theory and neural network was established. The monitoring model benefits from a strong nonlinearity mapping ability and thus can be used to analyze the detailed characteristics of seepage monitoring data.

(3) Considering the deficiency of a single monitoring model, an integrated monitoring model based on maximum entropy theory was established and found to improve the predication accuracy of seepage status determination for earth-rock dams.

(4) Through the application of the three monitoring models to a measuring point of an earth-rock dam influenced by rainstorms, we found that the three models have acceptable precision in fitting and predicating the seepage status, thereby providing technological support for the seepage monitoring of similar earth-rock dams.

\section{Competing Interests}

The authors declare that they have no competing interests.

\section{Acknowledgments}

This work was supported by the National Natural Science Foundation of China (Grant nos. 51579085, 41323001, 51139001, and 51279052), Project Funded by China State Key Laboratory of Hydrology-Water Resources and Hydraulic Engineering (Grant no. 20145028312), Jiangsu Province "333 High-Level Personnel Training Project” (Grant no. 2016B1307101), Open Fund of Key Laboratory of Earth-Rock Dam Failure Mechanism and Safety Control Techniques, Ministry of Water Resources (Grant no. YK914022), and Huai'an Water Conservancy Academician Workstation.

\section{References}

[1] M. Li and F. Wang, Design and Construction of Earth Rock Dam, China Waterpower Press, Beijing, China, 2011.

[2] T. V. Panthulu, C. Krishnaiah, and J. M. Shirke, "Detection of seepage paths in earth dams using self-potential and electrical resistivity methods," Engineering Geology, vol. 59, no. 3-4, pp. 281-295, 2001.

[3] M. Lamea and H. Mirzabozorg, "Simulating nonlinear behavior of AAR-affected arch dams including detection of crack profiles," Arabian Journal for Science and Engineering, vol. 40, no. 2, pp. 329-341, 2014.

[4] C.-H. Wu, S.-C. Chen, and Z.-Y. Feng, "Formation, failure, and consequences of the Xiaolin landslide dam, triggered by extreme rainfall from Typhoon Morakot, Taiwan," Landslides, vol. 11, no. 3, pp. 357-367, 2014.
[5] Z. Wu, Safety Monitoring Theory and Its Application of Hydraulic Structures, Higher Education Press, Beijing, China, 2003.

[6] H. Huang and B. Chen, "Dam seepage monitoring model based on dynamic effect weight of reservoir water level," Energy Procedia, vol. 16, pp. 159-165, 2012.

[7] B. J. Li and C. T. Cheng, "Monthly discharge forecasting using wavelet neural networks with extreme learning machine," Science China Technological Sciences, vol. 57, no. 12, pp. 24412452, 2014.

[8] H. Loussifi, K. Nouri, and N. B. Braiek, "A new efficient hybrid intelligent method for nonlinear dynamical systems identification: the Wavelet Kernel Fuzzy Neural Network," Communications in Nonlinear Science \& Numerical Simulation, vol. 32, pp. 10-30, 2016.

[9] B. Doucoure, K. Agbossou, and A. Cardenas, "Time series prediction using artificial wavelet neural network and multiresolution analysis: application to wind speed data," Renewable Energy, vol. 92, pp. 202-211, 2016.

[10] H. Gzyl, E. ter Horst, and G. Molina, "Application of the method of maximum entropy in the mean to classification problems," Physica A, vol. 437, Article ID 16220, pp. 101-108, 2015.

[11] H. Cui and V. P. Singh, "Maximum entropy spectral analysis for streamflow forecasting," Physica A: Statistical Mechanics and Its Applications, vol. 442, pp. 91-99, 2016.

[12] F. A. N. Palmieri and D. Ciuonzo, "Objective priors from maximum entropy in data classification," Information Fusion, vol. 14, no. 2, pp. 186-198, 2013.

[13] A. SaiToh, R. Rahimi, and M. Nakahara, "A quantum genetic algorithm with quantum crossover and mutation operations," Quantum Information Processing, vol. 13, no. 3, pp. 737-755, 2014.

[14] H.-L. Liu, "Acoustic partial discharge localization methodology in power transformers employing the quantum genetic algorithm," Applied Acoustics, vol. 102, pp. 71-78, 2016.

[15] E. Pomponi, A. Vinogradov, and A. Danyuk, "Wavelet based approach to signal activity detection and phase picking: application to acoustic emission," Signal Processing, vol. 115, pp. 110-119, 2015.

[16] A. Alhasan, D. J. White, and K. De Brabanterb, "Continuous wavelet analysis of pavement profiles," Automation in Construction, vol. 63, pp. 134-143, 2016.

[17] M. A. Goulart, L. Sanches, M. T. Vilani, and O. B. P. Júnior, "Analysis of evapotranspiration by Morlet wavelet in area of Vochysia divergens Pohl in Pantanal," Revista Brasileira de Engenharia Agricola e Ambiental, vol. 19, no. 2, pp. 93-98, 2015. 


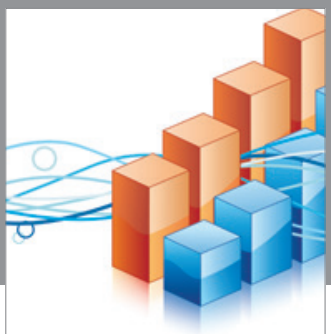

Advances in

Operations Research

vatem alat4

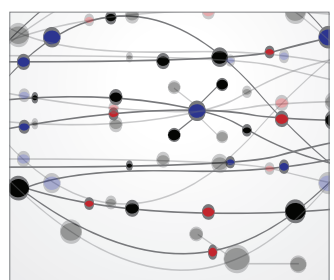

\section{The Scientific} World Journal
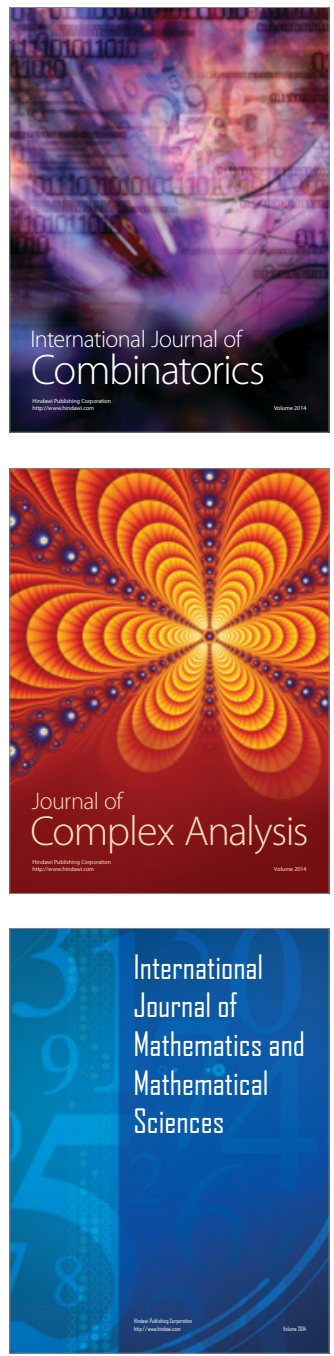
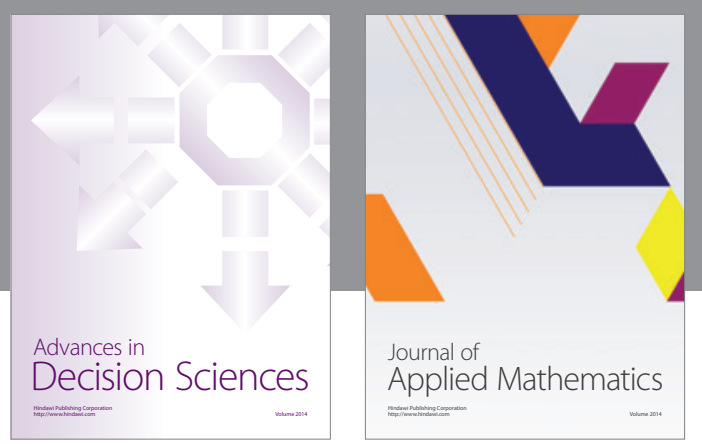

Algebra

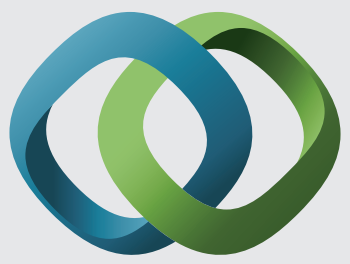

\section{Hindawi}

Submit your manuscripts at

http://www.hindawi.com
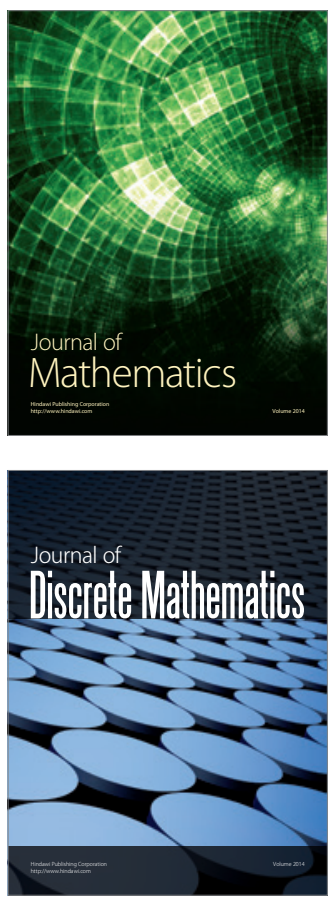

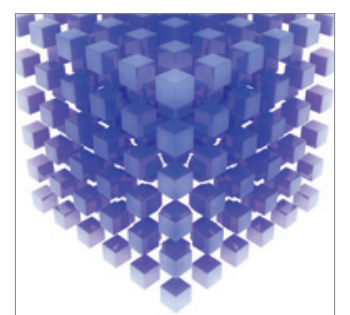

Mathematical Problems in Engineering
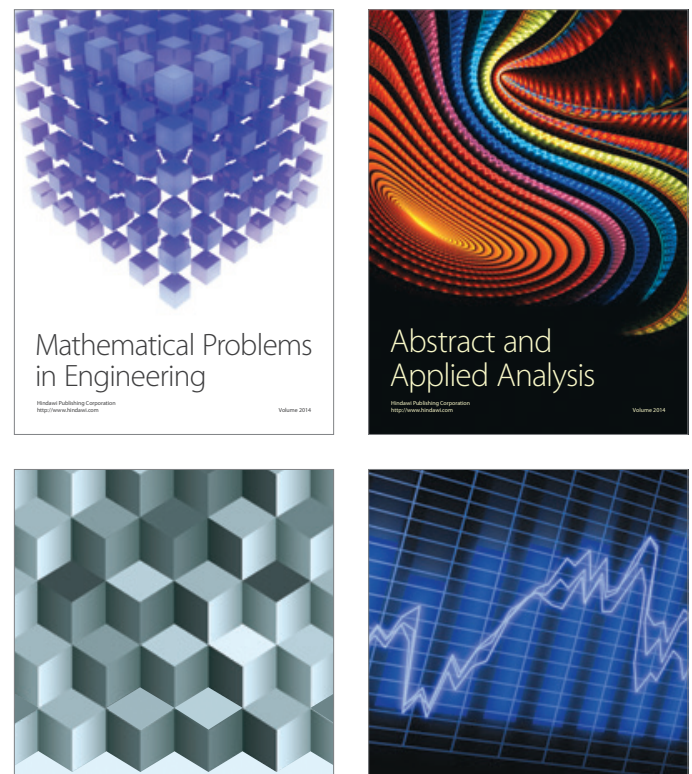

Journal of

Function Spaces

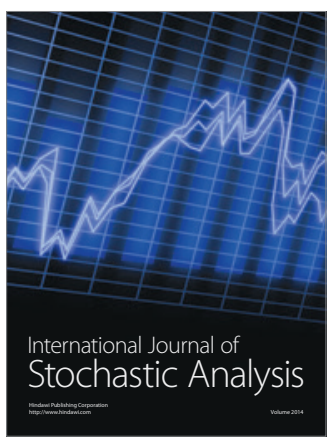

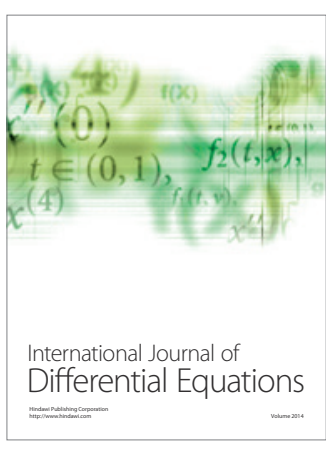
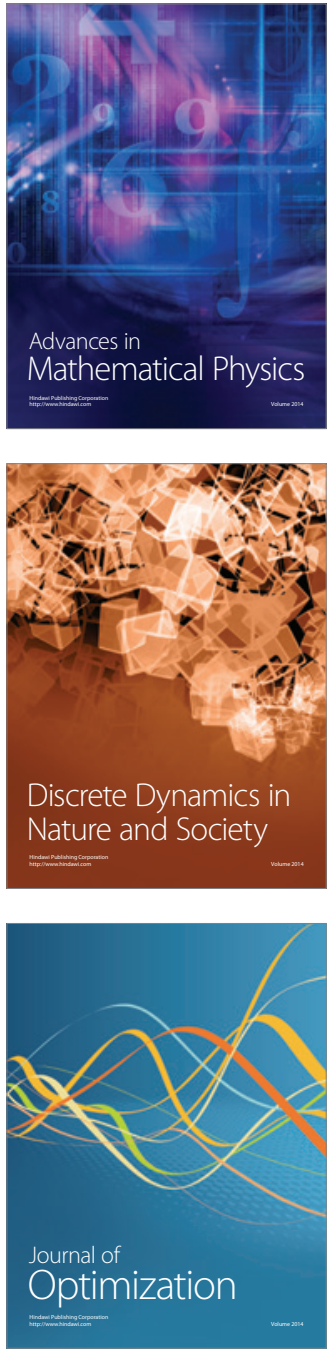